The Geographical Journal of Nepal

Vol. 14: 171-188, 2021

DOI: https://doi.org/10.3126/gjn.v14i0.35558

Central Department of Geography,

Tribhuvan University, Kathmandu, Nepal

\title{
People, place, and space: Theoretical and empirical reflections in studying urban open space
}

\author{
Krishna Prasad Timalsina \\ Ph.D. Student, Central Department of Geography, Tribhuvan University \\ Corresponding Email: krishnadhading@hotmail.com \\ Received: 20 November, 2020; Accepted: 02 December, 2020; Published: March 2021
}

\begin{abstract}
People, place, and space are the main domain of spatial research which is widely discussed in the geographic discipline. Geographers always focus on the meanings related to space and human interactions to explain people, place, and space. The concept was explained by Richard Harsthrone (1959), Fred E Lukermann (1964), David Harvey (1969), Henri Lefebvre (1974), Yi-fu Tuan (1974), Edward Relph (1976) and Doreen Massey (2005), etc. As a human geographer, Yi.fu Tuan has a great contribution to explain people-place relations and further explained by Relph, Massey, and other scholars. Grounding on the geographic research traditions, this paper presents the concept of people, place, and space reviewing the historiographical literatures and some empirical research studies on people-space relations. Theorists have argued that people and space are deep-rooted in studying place attachment creating people's sense of place. People's actions and behaviors create meaning through their individual and communal behaviors in that space where they live and interact. Moreover, theoretical perspectives argue that placemaking is always associated with the social and cultural dimensions of a society. Empirically, as an indigenous society, people from the core area of Kathmandu Metropolitan City (KMC) have been perceiving urban open space as a commonplace for social and cultural life activities whereas migrants'people living in the newly growing settlements have been perceiving the open space as a place for recreation and social capital enhancement.
\end{abstract}

Keywords: People, place, space, place attachment, public place, urban open space 


\section{Introduction}

The study of people, place, and space is the major focus within the field of geographical research. Geographers always focus on the meanings of space and human interactions to explain people, place, and space relations. Space itself will have no meaning unless people create meaning to it. Space and human interactions create meaning for any space through human behavior and actions on that space (Relph, 1976; Tuan, 1977). The meaning of space is also associated with social, cultural, and geographical contexts. The meaning of space to different societies may have different because society uses spaces differently in their different social and cultural contexts. Space in the urban areas has a different meaning and has more value than rural areas as urban planners and urban authorities always give attention to public space management in the urban context. To some, space is a social place for sharing people's feelings, experiences, knowledge, interaction between them; and to others. It is a place for physical exercises and places for health improvement. Moreover, some others have discussed the importance of space as disaster risk management and enhancing societal well-being (UN-Habitat, 2018; MoHA, 2019) in urban contexts. However, space value is closely associated with the decreasing open space with respect to the demand of land for different urban uses in the cities. But space as a place should be looked at through how people utilize space in different social and cultural contexts. This paper explores the space as a locational extent to which urban communities value it for different functions of urban life, and the place is the human attachment to a space created by the behaviour of people reflecting their everyday social, cultural, recreational, and health-related life activities. So, the debate of people place relations is always related to human attachment through their life activities.

Terminologies in the academic discussions about open space and public open space have been found interchangeably used. To define, public open spaces are those spaces that are available to urban residents without any restriction for social, cultural, environmental, economic, and political uses (UN-Habitat, 2018). Therefore, the public open spaces are shared resources, which are not closed or blocked up and provide access for people and express conditions of public life, civic culture, and everyday social life activities (Woolley, 2003). But the open spaces are all types of open spaces that may be public or private but these spaces have contributed to urban society for environmental benefit and shaping the urban physical form. Both public open space and open space underpin many social, cultural, ecological, and economic activities that are essential to the healthy functioning of urban life and the environment although they may have different implications and values for the urban residents. 
There are different uses of open spaces in KMC. Residents in the core area have been using open spaces for their cultural events and recreational place whereas some other new settlements have been using open spaces for recreation, community activities such as yoga, physical exercise, sports, etc. and sometimes for economic activities to earn livelihoods (Shrestha and Shrestha, 2006; Chitrakar, 2015). There is still a significant number of populations earning on the open space in the informal sectors for their livelihoods (Timalsina, 2011). Although the open space implications in the urban contexts are diverse, there is a knowledge gap in studying how open space contributes to people, place, and space relations, and it needs to be a major concern among the urban authorities and professionals who are working in the field of urbanism.

Open space in the academic discourses has mostly been discussed urban designing perspectives as architects and urban planners have focused on it as a design component (Madanipour, 2003; Pradhan, 2003; Low and Smith, 2005; Shrestha and Shrestha, 2006; Chitrakar, 2015 and 2006). They give attention to allocate open space in the urban settlements to keep city greenery, healthy, and to maintain spacious city space. Enhancement of city environment, city sustainability, landscape morphology would be their major concern of designs. Therefore, open space for them is to make cities more resilient and sustainable keeping the city's landscape natural. It means their concern is always associated to retain the city's landscape lively and natural and therefore, their concern mainly focuses on the landscaping and the city's morphology rather than looking at through the space-human relational perspectives. But people-space relations and place building concepts are yet to integrate into the academic discourses.

Human geographers take open spaces as social creation arguing in the humanistic perspectives of 'human-space' interactions. The humanistic perspectives propose a definite but complex relationship between the character of specific places and the cultural identities of those who inhabit them (Campbell, 2018). The place is the creation of human-space interactions and it is always associated with people who behave in that space. As the city is a produced space for human settlement, diverse social, cultural aspects are bound within it. It means open space in the urban context is closely related to place identity as any public space reflects the social and people's attachment to it. This paper, therefore, presents some theoretical concepts about people, place, and space to describe how open spaces have been functioning as places and how people are closely associated to create meaning through human geographic perspectives. Therefore, theoretical review on people, place, and space first then followed by the empirical research on how open spaces have been functioning as a socio-cultural place in $\mathrm{KMC}$, and how the process of transformation of sites may change the meaning of space over time has been reviewed through the human geographical perspectives. These concepts 
were discussed through the different social and cultural contexts taking historical open spaces from indigenous residents of core urban settings and newly emerging open spaces from migrants' society of KMC as these spaces are common resources to urban inhabitants. The review findings provide to develop a conceptual framework for studying the dynamics of public open spaces in KMC.

\section{Methods and materials}

This is a review paper prepared based on reviewing the historiographical literature on people, place, and space worked out by scholars with a special focus on humanistic geographic perspectives. Scholarly works by Richard Harsthrone (1959), Fred E Lukermann (1964), David Harvey (1969), Henri Lifebvre (1974), Yi-fu Tuan (1974), Edward Relph (1976), and Doreen Massey (2005) were reviewed to get insights into humanistic perspectives of people-place debate. The literature was collected through an online search from different publications available on web surfing from August to October 2020. Similarly, empirical literature in the field of architectural planning and geography was collected through the online search from August to October 2020 and other published articles and books. The focus of such reviews was done to look at how space has been viewed as a place in architectural planning and geographic research in Nepal. To relate the theoretical concepts in the ground, two different open space sites (one pubic open space-Yatakha Bahal, ward no 25 from the core area and one open space-Suryamukhi Garden, ward no 32 from the fringe area of KMC) were observed. The non-participant observation ${ }^{1}$ was carried out in both spaces to see the people's behaviours how they have been using the space and creating a place to open spaces. Such non-participant observation was conducted to observe people's behavour in space and relate it with a theoretical understanding of people, place, and space debate in geography.

The focus of the theoretical review was to see how the people, place, and space concept was used to see the relations of people and spaces for the creation of place. Empirical research works on open spaces under urbanism were reviewed to get how public spaces were considered as a place from the different academic discourses, particularly from urban planning and geography. So, the methodology of this research paper is based on constructive criticism on the literature available on people, place, and space under

1 Non-Prticpant observation was carried out at the purposively selected sites to validate the empirical findings of the review. The researcher visited the sites three times a day (morning, afternoon and evening) to observe actitvied going on at the selected open spaces. During the observation, various uses of the open space, different functions going on over the open space, purpose of people's visit, space morphology, social and cultural reflections of the space, etc. were observed to get insights of the spaces to relate human-space interactions. 
the scholarly works with a special focus on human geography. Similarly, reflective constructivism was employed to look into different forms of place-making in the different urban settings from core and fringe areas through the observation methods. This method has been combined to get insights into how people in different contexts view space as a place in Kathmandu Metropolitan City. Methodologically this paper, therefore, is based on qualitative interpretivism.

\section{Results and discussions}

\section{Place and space}

Much discussions on the concepts of place and space throughout the history of geographical research have been done in literature. As space and place together define the nature of geography, spatial analysis is at the forefront of geographical research locating space and place at the centre. Places are natural laboratories for the study of complex relationships among processes and phenomena (NRC, 1997) which human geographers have been focusing more on it. Geographers are confident of both the meaning of space and the methods suited to its analysis and therefore, a place like space lies at the core of geographical discipline which Tuan explains that modern analysis derives its substance from man's interactions with space which he has termed as 'sense of place' (Tuan, 1977). In the geographical literature, the place has been given several meanings; as a location, the place is one unit among other units to which it is linked by a circulation net, and it has more substance than the word location suggests. The place is thus a unique entity that has a history and meaning (Lukermann, 1964). The place embodies the experiences and aspirations of a people which is not only a fact to be explained in the broader frame of space, but it is also a reality to be clarified and understood from the perspectives of the people who have given it meaning (Campbell, 2018). The creation of meaning by the human interactions on space is a place that is therefore associated with human interactions with space.

In the early nineteenth century, geographical analysis was characterized by environmental determinism and historicism. In 1959 Hartshorne published 'Nature of Geography' which had turned geographical research in spatial distribution rather than the time which focus turned into social interests (Hartshorne, 1959). However, in the 1960s, geography was overcome by technical, statistical, and quantitative study and did not return to qualitative methods and humanistic focus until the 1970s (Compbell, 2018). In the 1970s, scholars such as Karl Marx described the importance of space as socially produced and consumed rooting geographical research on social dimensions of relating space-human interactions (Hubbard and Kitchen, 2011). Space and place then came into more discussions in human geography as the main discourse. People, place, 
and space, therefore, matter in geographical analysis after 1970s as human geographic perspectives.

Lefebvre in 1974 published 'The Production of Space' which introduced space as perceived space- 'activities through which society develops and reproduces its spatiality'; conceived space- 'defined by planners, architects and other specialists'; and endured space- 'users'space experienced lived every day'. According to Lefebvre, space changes over time, and its symbolic associations with it are always changeable (Lefebvre, 1974). Lefebvre's concern was of how the spatial experience has changed over time depending upon social circumstances. Meanwhile, Hubbard shifted the analytical focus of human geography from social space to lived-in space then followed by Yi-fu Tuan who adds that space does not have an inherent scale but instead is created by emotional attachment through fields of care (Tuan, 1977; Hubbard and Kitchen, 2011). Now spatial analysis in geography inherently came into social processes and human attachments giving attention to 'place' which is emphasized by Adams (2016) 'the geographic tradition of trying to understand the meanings and processes of place - their material and symbolic qualities - as well as the range of peoples and social relations that continuously define and create social and spatial contexts' (Adams, 2016). People in space, therefore, create social relations and dynamics in studying human space relations.

Similarly, David Harvey interpreted Marxist's theory pointing out the paradox as globalization depends on a sense of place because history, culture, and landscape are crucial in perpetuating special processes of capital accumulation (Harvey, 1969; Goheen, 1998; Campbell, 2018). Capital formation is closely related to people-space relations and cultural associations. Edward Relph (1976) argues that human geographers need to seek a more human-centric approach and an empathetic understanding of the lived experience of place. Relph stresses that there can only be a sense of place when the bond between people and place is deep-rooted (Relph, 1976). Describing the place from a humanistic perspective, Phil Hubbard and Ras Kitchin, 2011 have explained place as;

Places are fundamental in providing a sense of belonging for those who live in them, humanistic perspectives propose a definite but complex relationship between the character of specific places and the cultural identities of those who inhabit them. Against this, materialist perspectives propose that cultural battles create explicit inequalities in the way that space is occupied and used by members of different groups (Hubbard and Kitchin., 2011)

In the 1990s, human geography turned into a postmodern age which has focused its inquiry that tied the study of geography with social justice and focused on pluralities, 
binaries, positionalities, and deconstruction (Peet, 1998; Pieterse, 2002; Campbell, 2018). Focusing on the spatial dimension of society, postmodernists argue that realities are socially constructed; the way people think and talk about, social realities affects agendas, policies, laws (Pieterse, 2002). Meanwhile, the geographical analysis turned into the 'geographic representations' as a Geographical Information System (GIS) focused on the analysis of how spatial meaning is constructed and how spatial dynamics are represented visually. Human geography exports the concept and study of space to other disciplines in the social sciences and humanities (Campbell, 2018). Human geographers are now looking at spatial analysis parallelly to social dimensions of space and mapping social phenomena into the visualization of the geographic world. Therefore, geographers are giving attention to spatial representation and integrate the concepts and methods from many other disciplines and interact with other fields, including computer science, statistics, mathematics, geodesy, civil engineering, cognitive science, formal logic, cognitive psychology, semiotics, and linguistics (NRC, 1997). The goal is to produce a unified approach to spatial representation and to devise practical tools for representing the complexities of the world and for facilitating the synthesis of diverse kinds of information and diverse perspectives. Integrations of diverse disciplines now have been the popular approach in the field of geographic analysis.

Massey (2005) in her book 'For Space' discusses the political implications of the ongoing privatization of space. She has argued of place stating that place has importance as; i) places do not have single identities but multiple ones; a product of interrelations, ii) places are not frozen in time, they are processes; space as the existence of plurality, iii) places are not enclosures with a clear inside and outside; space is as always under constructions. The idea is that space and time are intimately connected to each other. Her contributions specifically framed a relational approach to understanding the debates on space and place in regional studies as she explains;

One way of thinking about a place is as particular moments in ... intersecting social relations, nets of which have over time been constructed, laid down, interact with one another, decayed and renewed. Some of these relations will be, as it were, contained within the place; others will stretch beyond it, tying any particular locality into wider relations and processes in which other places are implicated too.... The global is in the local in the very process of the formation of the local (Massey, 2005).

Her argument indicates three key sayings for understanding space; first, as the product of interrelations, which constituted through interactions; second, as a sphere of multiplicity in which distinct trajectories and heterogeneity co-exist; and third, as always in the process of being made or produced (Massey, 2005). 
Therefore, space according to her is the understanding as an ongoing production that may change over time. She puts her thoughts that space inflects our understandings of the world, our attitudes to others, our politics which is also argued by Harvey in 2006 (Harvey, 2006). It affects the way we understand globalization, the way we approach cities, the way we develop, and practice, a sense of place (Massey, 2005). The argument is strongly connected to society in space which means to relate people in space and also with the political economy of space as argued by Harvey (Harvey, 2006).

Summarizing the review of the historical perspective of space and place in human geography, it is concluded that geography has a long tradition of attempting to understand how different processes and phenomena interact at global, regional, and local levels, including an understanding of how these interactions give places their distinctive character (NRC, 1997). Therefore, space and place have different dimensions of understanding human behaviour on different scales. Space and place interaction thus, are a focused area of research within human geography. Within studies of urban open space, perspectives of place and space could be linked to see how people create meaning to any space reflecting their culture, identity, and how they are bound to that space. The shift of human geographic trend of analysis scene was moving from physical dimensions to more sociospatial dimensions. Scholars like Richard Harshrone, Fred E Lukermann, Edward Relph, had focused more on physical aspects of spatial distribution rather than as a process and time. However, Yi-fu Tuan, Henri Lefebvre, David Harvey, Doreen Massey focused more on patterns and processes that are more relevant to the time factor and argued how the social process is determined to changing the spatial process over time. The commonalities among the scholars are that people, space, and place are interlinked to each other that may shape and reshape the social process and are varied according to the social and cultural practice of society although the earlier geographers had focused on physical aspects of analysis rather than human-space interactions.

\section{Sense of place and place-making}

Coming to this point of looking at place and space theoretically, people, place, and space are interconnected to each other. Space without human actions and attachments has no significant meaning. People with space attachment are what sense of place is all about which has been discussed more in human geography. Subjective human reactions to spaces may vary according to the socio-cultural and environmental contexts. The idea of a sense of place has been much discussed 
in the domain of human geography and then in other fields. Defining the sense of place, Walkie (2016) has explained as;

With roots in early forms of humanistic geography, the concept appears in various forms in a considerable body of works expanding on human experience, memory, imagination, emotion, and meaning; accordingly, it is a core value in a broad and varied range of endeavors from theory to practice. In sum, the sense of place contributes depth and understanding to what it means to be human (Walkie, 2016).

A sense of place therefore describes the human relationship with space, expressed in different dimensions of human life: emotions, biographies, imagination, stories, and personal experiences (Basso, 1996). Place attachment reflects a bond between people and space, and place reflects symbolic meanings people ascribe to spaces (Adam, 2016). The sense of place varies among people, communities, cultures, and throughout one's lifetime. This means people may attribute various meanings to the same place in relation to its ecological, social, economic, cultural, aesthetic, historical, or other aspects which may change over time (Basso, 1996; Massey, 2005; Stanley et al., 2014; Adam, 2016). A sense of place evolves through personal experiences and defines how people view, interpret, and interact with their world (Russ et al., 2015). The sense of place differs in cities and rural settlements. The sense of place in the cities echoes the intersections of culture, environment, history, politics, and economics, and is impacted by mobility, and blurred boundaries between the natural and built environment (Adam, 2016). People residing in some place may have a different sense of that place than those living in another place and environment. People traveling from one geographic region to another region may have different perceptions and understandings of that place. Therefore, the sense of place varies according to time spent at a particular space and geography he/she belongs to.

People's actions and behaviors create/give meaning to any space. People create meaning to any space through their individual and communal behaviors in that space where they live and interact. A community develops a place which is closely related to its culture, communal behaviour, and practices. Therefore, dimensions of open space in the urban contexts may vary according to social, cultural behaviors that society develops. Looking at urban open space through human geographic perspectives, it helps to build a sense of community, civic identity, and culture and it facilitates to bond social capitals, cultural development, and community revitalization (Anderson, 2016). Soja (1996), argues that space is understood as a physical and social landscape that is imbued with meaning in everyday place-bound social practices and emerges through processes that operate over 
varying spatial and temporal scales (Saar and Palang, 2009). Therefore, society creates a place for any space through social practices in everyday interactions with it.

Studying place attachment has been a growing concern among urban planners and architects in recent decades as open spaces in the cities are meant to place building for city dwellers (Chitrakar, 2015). This has also been a major concern among human geographers as the place has special meaning to human geographers while analyzing the dynamics of human-space relations (Tuan, 1977; Harvey, 1969; Ralf, 1979; Massey, 2005). Urban planners and architects have argued the built environment as the most significant designs that affect our daily lives and therefore in the same way public spaces; such as parks, public squares, open plaza, green areas affect our daily life (Anderson, 2016). Their concern seems to be objective space as architects and urban planners deal with designed space to urban open space. Contemporary urbanists have been studying human behavior and have presented their findings of social life and urban spaces as placemaking in different urban studies. This indicates urbanists have also trying to integrate social actions and behaviors in designing the city in line with humanistic perspectives. Their concerns seem to be 'city for people' meant to connect humanistic perspectives in the design elements of open space within a city; however, the depth of relating 'people in a space' is still lacking.

The discussion above on the sense of place is linked to give a picture of how urban spaces play important role in designing a city and how people are associated with place attachment. Theoretical understanding of people, place, and space in studying urban open space can be considered as a place in the urban context that could be looked through the place making perspectives. As different socio-cultural contexts reflect different perspectives of placemaking, it is imperative to look into how people in the urban areas of $\mathrm{KMC}$ have been creating and assembling the meaning to the public space in their daily life activities. Open spaces in KMC are decreasing rapidly through the process of encroachment, uses change, and rapid urbanization. Data reveals that from 1980 to 2019 , the built-up area in KMC is increased by $40.02 \%$ whereas agriculture and open area is decreased by 52.85 percent and 1.76 percent respectively (Timalsina, 2020a). The figure presents how open spaces in the city are decreasing limiting public open space. There are different patterns of functional uses of open spaces in KMC in the different social settings; however, public open spaces are well recognized socially as these provide a place for physical and social well-being and these vary according to social and cultural settings (Timalsina, 2020b). Some empirical studies on open space have been reviewed to see how people have been perceiving open space as a place in different urban settings (among the indigenous and migrants communities of KMC). 


\section{Empirical studies}

Various scholars have discussed in their research works about people, place, and space. Spreiregen in 1965 has pointed out that traditional urban spaces are simply the creation of their times. Open spaces form simply follow nature and respect the culture of their society. The argument is that urban spaces are the creation of times reflecting social process and cultural practices and pose how community actions and behavior inherently create meaning to the spaces where they live in. The concept is that people in the society have been giving meaning to their space in different patterns not only in designing but in the whole sets of physical, social, cultural landscapes of space. Spaces have gradually been turning into place through human actions, behaviors, socialization, and development of the society itself. The empirical studies on open spaces and public spaces have focused on the design sides of open spaces in the field of urban planning and architecture. Recently, some of the studies on urban space have highlighted the typology, functions, and locational advantages of how these can be implied in urbanism (Pokhrel and Khanal, 2015). An inventory study has identified that there are different types of open spaces in KMC including private, government, institutional, public, and Guthi, etc. (KVDA, 2015). Although the categories of open spaces were defined, its functional uses and implications were not elaborated much. These typologies of open spaces have different uses and functions in different social and cultural settings which has not been explored through people-space perspectives.

The historical open spaces are examples of successful urban open spaces that have excellent physical design and succeeded in making a built environment (Chitrakar, 2015; Maharjan, 2018). Bahas and courtyards are the major public open spaces which have been critical sites of cultural, political, and economic life from early civilizations to the present day in core urban settings in Kathmandu (RECPHEC, 2016). Baha is a Buddhist Monastery and derives its name from the Sanskrit word Bihara, meaning joy or enchantment and thus is a place of religious bliss (Tiwari, 2001 and Chitrakar, 2006 and 2015). The Bahas are generally constructed by a family and their descendants reside in it for generations (Maharjan, 2018). A community is formed to use and protect the Bahas as these are surrounded by the local residents and they have common rights to use them. These Bahas are having characteristics of a square or rectangular space bounded by buildings on all sides, surrounding buildings built on a raised platform called Falcha, ground paved with brick or stone, generally centrally placed Chaitya, often the presence of a well, the building opposite to the main entrance houses a Guthi with idols of deities in the ground floor (Shrestha, 1981; Chitrakar, 2015 and 2006; Maharjan, 2018). The characteristics are also the reflections of Newari place identity as cultural practices from the historic Malla regime of Nepal. 
The Bahas as the open spaces in the core city present local communities' identity and their cultural, architectural, and historical representations. Keeping Bahas in the traditional settlements of Kathmandu Valley was the historical practice of placemaking as society feels to have their sense of place and their identity would be reflected in them. The Bahas of KMC shows the unique place created by local communities giving their sense of place and cultural identity among the Newar communities. There are several such courtyards which are historical assets that reflect the typical Newari culture and pose their cultural identity. These open spaces in the urban core area of Kathmandu are being dedicated mostly for cultural activities and the people have given some cultural meaning to it. While looking at the uses of these public spaces, these spaces are being used for cultural activities e.g. Jatra, and other cultural events; for social activities e.g. Bhoj, social gathering, interactions; and for grain processing, drying when there was dominant agriculture base economy of Kathmandu (RECPHEC, 2016; Maharjan, 2018). Architectural layout planning at that time of such open spaces therefore, would be more focused on cultural reflections on them. Later on, architects and urban planners have been trying to connect places with people while designing it. However, the historic examples and the contemporary trend of open space design in the valley are found unsatisfactory as the built environment is not conducive to creating a better public realm (Chitrakar, 2015). It implies the changing scenario and practice of open space development in the emerging settlements of Kathmandu.

Open spaces in newly growing settlements in KMC have implicitly linked to community identity reflecting their sense of place. Development of open space as an embedded concept with temples, churches, mosques, parks, playgrounds, recreational places, etc. on the premises of new settlement and planned developed areas is not only the architectural design but reflects community identity. However, the open space development in the fringe areas of $\mathrm{KMC}$ is more dynamic than the core area as these newly growing settlements are more diverse and heterogeneous in social structures. Uses of open spaces in these societies have been different than those of core areas as the spaces have been mostly using open space as a place for recreation, interaction, community networking, health improvement through yoga, sports, and physical exercises. Besides, the morphology of open spaces among the newly planned development areas poses spacious planning for sports activities such as badminton, table tennis, football, volleyball, etc. Besides, walking routes, rest places, recreational parks, fountains, ponds, temples, greenery, etc. are also considered within such open space development (ADB, 2017). Therefore, the physical attributes and morphology of such public open space in the traditional and new settlements area of KMC are visibly distinct patterns of uses and functions according to social and cultural settings. 
Empirical data collected through the field observation from two sites reveals that the uses of public open spaces in core urban areas (dominantly indigenous residents) and fringe areas (dominantly migrants residents) reveal a different scenario. Developing social capital through networking, interactions, communications, and organizing communities' social and cultural events as well as physical health enhancement through sport, run, walk, yoga, meditations, etc. are the forms of using open space in both settings. Observational data ${ }^{2}$ reveals that there were 152 visitors encountered at the selected open space from core urban open space and 290 visitors at the selected open space in the fringe urban area. The observational result is that visitors in the core area have been using public open spaces for cultural and religious activities (36.2\%), organizing community meetings $(21.1 \%)$, walk/run/yoga and exercises $(18.4 \%)$, recreational and entertainment (14.5\%) and sports (9.9\%). Similarly, people from the fringe area visit open spaces for or g a n i z i n g c o m m u n i t y meetings (6.9\%), walk, run and yoga (41.4\%) recreation and entertainment (31\%), sports (20.7\%). It reveals that there are different patterns of visiting for the use of open spaces Table 1: Activities Observed at the Urban Open Space in different urban

\begin{tabular}{|l|l|c|c|c|c|}
\hline S.No. & \multicolumn{1}{|c|}{ Used for } & $\begin{array}{c}\text { Core } \\
\text { Area }\end{array}$ & Percent & $\begin{array}{c}\text { Fringe } \\
\text { Area }\end{array}$ & Percent \\
\hline 1 & $\begin{array}{l}\text { Cultural and } \\
\text { religious activities }\end{array}$ & 55 & 36.2 & - & - \\
\hline 2 & $\begin{array}{l}\text { Organizing } \\
\text { community events } \\
\text { and meetings }\end{array}$ & 32 & 21.1 & 20 & 6.9 \\
\hline 3 & $\begin{array}{l}\text { Walk/run/Yoga } \\
\text { and exercises }\end{array}$ & 28 & 18.4 & 120 & 41.4 \\
\hline 4 & $\begin{array}{l}\text { Recreation/ } \\
\text { entertainment }\end{array}$ & 22 & 14.5 & 90 & 31.0 \\
\hline 5 & $\begin{array}{l}\text { Sport related } \\
\text { (Badminton) }\end{array}$ & 15 & 9.9 & 60 & 20.7 \\
\hline & Total & $\mathbf{1 5 2}$ & $\mathbf{1 0 0}$ & $\mathbf{2 9 0}$ & $\mathbf{1 0 0}$ \\
\hline
\end{tabular}

Source: Field Observation, 2020

settings in the city (Table 1). The patterns of visit and uses of open space are therefore closely associated with the social and cultural settings of the particular community.

Architects and urban planners have been focusing on the layout designing to open spaces in the newly emerging settlements from a recreational point of view. Their main concerns seem to protect biodiversity, environmental conservation, maintain greenery, and heritage conservation upholding the physical morphology and local cultural

2 Observational data presents the number of visitors per day encountered at the selected sites during the field observation. The researcher was visited these places three times a day (morning, afternoon and evening) to observe the details of visitors' activities and averaged to get the total number of three consecutive days visitors' data. The number of visitors may vary according to the seasons and the cultural and ritual purposed of the indigenous Newar community because the frequency of cultural and religious activities is more in some specific seasons of Newar communities. 
landscape of the society. They always care about the urban landscape, morphology, and spacious planning for city dwellers. But it is very important that people have always been giving their root knowledge to create meanings to space and therefore they wish to get a reflection of their cultures, identities, aspirations in the space where they live in. Therefore, the design of open space within the city is also needed to look at social aspects and their identity to be reflective in them. Though there are significant differences in the forms and process of creating places on space between two different urban settings (Core urban settings and new urban settings), these practices are always inherently coming culturally. Bahas and courtyards of core urban areas best illustrate the cultural reflections of the people whereas outer areas reflect some recreational aspects that people prefer to see the open space in the long run.

\section{Conclusion}

This is a review-based article prepared by reviewing the literature on people, place, and space. The main objective of this paper is to assess urban space through perspectives of people, place, and space by reviewing the major scholarly works. The literature on people, place, space, and sense of place has been reviewed to get insights into how these terminologies are interrelated and how people reflect their behaviors on space. Major works on space and place by the scholars such as Richard Harsthrone (1959), Fred E Lukermann (1964), David Harvey (1969), Henri Lefebvre (1974), Yi-fu Tuan (1974), Edward Relph (1976), and Doreen Massey (2005), etc. who have primarily worked on human-space interactions have been reviewed. Reviews on empirical literature on urban space were done in the urban context to see how people have been creating meaning to space as a place in different settings and contexts (indigenous and migrants) taking the case of KMC. Moreover, the review finding was linked to the ground through the nonparticipant observation to see how the concepts are reflected in different urban settings. One each public open space from both urban settings (core urban area representing indigenous community and a fringe urban area representing the migrants' community) was observed in three consecutive days to get insights into the public uses and behaviour to create space to place.

The theoretical literature on people, place, and space was discussed much under human geography emphasizing human-space relationships and their dynamics. Theorists have argued that people and places are deep-rooted with place attachment creating a sense of place. People's actions and behaviors create meaning to any space through their individual and communal behaviors in that space where they live and interact. This interaction creates deep-rooted relationships between people and space to create meaning of space and the meaning varies according to the socio-cultural dynamics of 
the society. Society gives meaning to space through its social and cultural contexts. It has been found that communities have been giving meaning to space from the historical period in $\mathrm{KMC}$ as the Bahas of core urban areas reflect the cultural identities of local communities (Newar communities). Open spaces in the core urban area of KMC have a typical Newari identity with their cultural sense of place whereas newly growing settlements have been viewing a diverse sense of place focusing on recreation and wellbeing. But the trend of creating meaning from space into place has been changing over time and it varies according to the social and cultural contexts. Open spaces within the core urban areas have been reflecting as cultural spaces whereas outer areas pose more physical and social reflections. Uses patterns vary in both settings as the core area mostly reveals the cultural uses and fringe areas for physical and social uses. The finding is that people have always been giving their social knowledge to create meanings to space according to their social, cultural settings and it changes over time.

\section{References}

ADB. (2017). Land pooling projects in Nepal: A consolidated Document. Regional Capacity Development Technical Assistance (R-CDTA), ADB/OIE, Kathmandu

Adams, J. D. (2016). Sense of place. The nature of cities. New York: Thunder Bay, Seattle and Ithaca.

Anderson, C. (2016). Public space and the new urban agenda. The journal of public space, Un-habitat-III. I, 1.

Basso, K.H. (1996). Wisdom sits in places: Notes on a Western Apache landscape. In Feld, S. and Basso, K.H. (Eds.), Senses of place (pp. 53-90). Santa Fe: New Mexico.

Campbell, C.J. (2018). Space, place and scale: Human Geography and spatial history. Past and Present. Volume 239, Issue 1, May 2018, Pages e23-245. https://doi.org/10.1093/pastj/gtw006

Chitrakar, R. M. (2006). A study of historic urban squares of Kathmandu Valley. (MUD Dissertation), The University of Hong Kong, Hong Kong.

Chitrakar, R.M. (2015). Transformation of public space in contemporary urban neighborhoods of Kathmandu valley, Nepal: an investigation of changing provision, use and meaning. (Ph.D. Thesis), School of Civil Engineering and Built Environment Faculty of Science and the Engineering Queensland University of Technology. 
Krishna Prasad Timalsina/ People, place, and space: ...Vol. 14: 171-188, 2021

Goheen, P.G. (1998). Public space and the geography of the modern city. Progress in Human Geography, 22 (4), 479-496.

Hartshorne, R. (1959). Perspective on the nature of geography. Chicago: Rand McNally and Company.

Harvey, D. (1969). Explanation in geography. London: Edward Mold.

Harvey, D. (2006). The political economy of public space. In S. M. Low and N. Smith (Eds), The Politics of Public Space. New York, NY: Rutledge.

Hubbard, P. and Kitchen, R. (eds). (2011). Key thinkers on space and place. London/ Thousand Oaks/ Singapore/New Delhi: Sage publication.

KVDA. (2015). Atlas of open space. Kathmandu: Kathmandu Valley Development Authority, Kathmandu.

Lefbvre, H. (1974). The production of space. UK, USA: Blackwell Publishing.

Low, S. and Smith, N. (2005). Introduction: The imperative of public space. In Low, S. and Smith, N. (Eds.), The politics of public space. London: Rutledge.

Lukermann, F. E. (1964). Geography as a formal intellectual discipline and the way in which it contributes to human knowledge. Canadian Geographer 8, 167-172.

Madanipour, A. (2003). Public and Private Spaces of the City. London; New York: Routledge.

Maharjan, S. (2018). How open spaces in Kathmandu Valley are shrinking? Centre for Investigative Journalism (CIJ), retrieved from https://cijnepal.org.np/openspaces-kathmandu-valley-shrinking/

Massey, D. (2005). For space. London/New Delhi: Sage.

MoHA. (2019). Nepal disaster report. Kathmandu: GoN, Ministry of Home Affairs.

NRC-National Research Council. (1997). Rediscovering geography: new relevance for science and society. National Academic Press.

Peet, R. (1998). Modern geographical thought. London/Thousand Oaks: WileyBlackwell Publication.

Pieterse, J. N. (2002). Development theory: deconstruction/reconstruction. London/ Thousand Oaks/New Delhi: Sage Publication.

Pokharel, R. P. and Khanal, N. R. (2018). Open space: Typology and distribution in Pokhara Lekhnath metropolitan city. The Geographical Journal of Nepal, 11: 
25-44. Central Department of Geography, Tribhuvan University, Kathmandu, Nepal

Pradhan, M. G. (2003). Urban Open Spaces in Kathmandu - Problems and Prospects. Vaastu, 5, 45-46.

Relph, E. (1976). Place and placelessness. London: Pion.

RECPHEC-Resource Centre for Primary Health Care. (2016). A study on public spaces of Kathmandu Metropolitan City for policy revision. Kathmandu: RECHPEC.

Russ, A., Peters, S.J., Krasny, M.E. and Stedman, R.C. (2015). Development of ecological place meaning in New York City. Journal of environmental education, 46(2), 73-93.

Shrestha, B. K., \& Shrestha, S. (2006). To Whom It May Concern - Privatization of Public Spaces: A Case of Dharahara - Sundhara Square, Kathmandu. Scitech Nepal, 9(2), 3-22.

Shrestha, M. N. (1981). Nepal's Traditional Settlement: Pattern and Architecture. Journal of Cultural Geography, 1(2), 26-43.

Spreiregn, P.D. (2009). Urban Design, the architecture of towns and cities. Pennsylvania State University: R.E. Krieger Publishing Company.

Stanley, B. W.; Stark, B.L.; Johnston, K.L. and Smith, M.E. (2014). Urban open spaces in historical perspective: a transdisciplinary typology and analysis. E-Journal of Research Gate. Retrieved from https://www.researchgate.net/ publication/268208067.

Timalsina, K. P. (2011). Struggling for livelihood: making a living in the urban informal sector. Germany: VDM Vorlag Publisher.

Timalsina, K.P. (2020a). Public open space in crises: Appraisal and observation from metropolitan Kathmandu. Journal of Geography and Regional Planning, 13 (4): 77-90. DOI: $10.5897 / J G R P 2020.0797$.

Timalsina, K.P. (2020b). Urban Open Space as a Place for Social and Physical Wellbeing: Narratives from two Different Urban Settings of Kathmandu, Nepal. Journal of Geographical Research, (upcoming).

Tiwari, S.R. (2001). The ancient settlements of Kathmandu Valley. Kathmandu: Centre for Nepal and Asian Studies.

Tuan, Y.-F. (1977). Space and place: The perspective of experience. University of Minnesota Press. 
Krishna Prasad Timalsina/ People, place, and space: ...Vol. 14: 171-188, 2021

UN-Habitat. (2018).Developing public space and land values in cities and Neighborhoods (discussion paper). Kathmandu: UN-Habitat.

Walkie, R. and George, F.R. (2016). Sense of Place. In Warf, B. (eds). Encyclopedia of Geography, DOI: http://dx.doi.org/10.4135/9781412939591.n1022.

Wooley, H. (2003). Urban open space. London and New York: Tailor and Francis. 